\title{
INFLUENCE OF THE ENVIRONMENT AND OCCUPATIONAL EXPOSURE ON THE OCCURRENCE OF Q FEVER
}

\author{
Erik Dorko ${ }^{1}$, Kvetoslava Rimárová1, Emil Pilipčinec ${ }^{2}$ \\ ${ }^{1}$ Department of Public Health, Faculty of Medicine, University of P. J. Šafárik, Košice, Slovak Republic \\ ${ }^{2}$ Department of Microbiology and Immunology, University of Veterinary Medicine and Pharmacy, Košice, Slovak Republic
}

\section{SUMMARY}

$Q$ fever, which is caused by Coxiella burnetii, is a worldwide zoonotic infectious disease and ruminants are the main reservoir for human infections. Humans become infected primarily by inhaling aerosols that are contaminated with $\mathrm{C}$. burnetii. Ingestion (particularly drinking raw milk) and person-to-person transmission are minor routes. Animals shed the bacterium in urine and faeces, and in very high concentrations in birth by-products. The bacterium persists in the environment in a resistant spore-like form which may become airborne and transported long distances by the wind. $Q$ fever is considered primarily an occupational disease of workers in close contact with farm animals or processing their products, however, it may occur also in persons without direct contact. To prevent the introduction and spread of $Q$ fever infection, preventive measures should be implemented including immunisation with currently available vaccines of domestic animals and humans at risk.

Key words: Q fever, Coxiella burnetii, environmental contamination, occupational exposure, preventive measures

Address for correspondence: Erik Dorko, Department of Public Health, Faculty of Medicine, University of P. J. Šafárik, Šrobárova 2,04180 Košice, Slovak Republic. E-mail: erik.dorko@upjs.sk

\section{INTRODUCTION}

Q fever was first described in 1937 by Edward Holbrook Derrick (1898-1976), while he was the director of the Laboratory of Microbiology and Pathology at the Queensland Health Department in Brisbane (Australia). In 1935, he was instructed to investigate a febrile illness among abattoir workers in Brisbane (1).

The disease is caused by the obligate intracellular bacterium Coxiella burnetii, which lives in the macrophages of the host but may survive outside the cell and can have two distinct antigenic phases I and II. Animals and humans develop antibody responses to both phases $(2,3)$. C. burnetii remains viable for months to years in the environment contaminating water and soil. Highlevel resistance to UV radiation, heat, desiccation, pressure, osmotic and oxidative stress, and disinfectant agents has been demonstrated (4-6).

Q fever is an infectious disease that occurs in all geographic and climatic zones, where the conditions support natural $C$. burnetii infection and circulation (7). Infected domestic animals (cattle, sheep, and goats but also pet animals, especially cats and $\operatorname{dogs}$ ), frequently with persistent and subclinical coxiellosis, are the main source of $C$. burnetii infection in humans, who become infected by direct contact with these animals, by environmental contamination (from animal excrements), and (indirectly) through processing or consuming animal products $(8-11)$.

Though Q fever can be considered primarily an occupational disease of workers in close contact with farm animals or processing animal products, it may occur also in visitors to areas at risk, travellers to areas with Q fever occurrence, even in innocent by- standers, etc. An uncontrolled transfer and movement of domestic animals seems to be responsible for the spread of disease (12).

Because human infection is not limited only to people in contact with animals, we would like to point to the importance of both profession and the environment as important risk factors associated with transfer of Q fever and recommend protective measures aimed at prevention of the development and spread of disease.

\section{Occurrence in Slovakia and European Countries}

In Slovakia, Q fever has been known since 1954 when outbreaks occurred among agricultural workers who contracted the infection from sheep and among workers of a textile plant who were exposed to contaminated imported cotton. Until the eighties of the 20th century the waves of epizootics and small epidemics appeared in factories processing cotton, wool, and hides, in a sheep farm, and on various agricultural premises. Large-scale vaccination of cattle carried out in the 1970s and 1980s, together with improved veterinary control of domestic animal transport within the country, could explain a decrease in the occurrence of human Q fever in Slovakia $(7,11)$. An exception was the explosive epidemic of Q fever in 1993 that affected 113 humans (13).

The first data about the occurrence of $C$. burnetii in Eastern Slovakia were published by Pospíšil (1956), who described the presence of antibodies in domestic animals and humans (14). The first epidemic of Q fever in the Eastern Slovakia occurred in 1962 in Bardejov district among a group of animal production workers. Another outbreak occurred at about the same time in Sokol'any village in Košice-country district, where 13 employees of a lo- 
cal cattle farm became ill. A further epidemic occurred among employees and visitors to a state farm and agricultural training centre in Bardejov district. Two neighbouring villages, Rochovce and Slavošovce in Rožňava district were the next affected in this sequence of Q fever epidemics. In spring 1967, 26 people in these villages became ill with $Q$ fever and two died. Repeated outbreak of Q fever occurring in 1969 and 1970 in a state cattle farm in Budulov village in Košice-country district with 54 human cases was one of the largest in Eastern Slovakia. An epidemic of Q fever involving 20 persons occurred in a sheep co-operative farm in the village of Družstevná pri Hornáde during sheep shearing in spring (15). In Slovakia, the occurrence of Q fever in domestic animals and humans has been probably reduced due to a largescale vaccination of cattle in the 1970s and 1980s (7).

Table 1 shows the number of cases and the incidence of $Q$ fever from the period 2001-2010 in selected European countries including Slovakia. In the last 10 years, Q fever is the most frequent in the following European countries: the Netherlands, Germany, Spain, Bulgaria, France, Croatia, Bosnia and Herzegovina, and the United Kingdom. Occurrence of this disease is also obvious in other European countries, where small outbreaks have occurred (16). Since 2007, there has been the world's largest outbreak of $\mathrm{Q}$ fever with over 4,000 notified cases. A large human cluster of Q fever was clearly linked to dairy goat and sheep farms with Q fever related abortion episodes (17). However, since in many countries reporting on $\mathrm{Q}$ fever cases is not required and many $C$. burnetii infections are inapparent, it is difficult to estimate the number of cases of the disease that actually have occurred (7).

\section{Routes of Pathogen Transmission}

The infectious agent is usually acquired by inhaling infected aerosols, often from products of conception in farm environments or abattoirs. Ingestion of contaminated dairy products has also been considered a possible route of infection; the tick transmission has been proven but is probably rare (18).
Every tick species, parasitising a susceptible host in a known area of endemicity can be expected to harbour and spread $C$. burnetii (12). Ticks transmit the agent vertically, i.e. transstadially and transovarially to their progeny and horizontally via bite or faeces to wild animals, especially rodents and birds (7). They are considered to be the natural primary reservoir of $C$. burnetii, responsible for the spread of infection in wild animals and for transmission to domestic animals and seem to play a central role in maintaining the viability of this pathogen in the environment (19). On the other hand, numerous epidemiologic data do not support an important role of ticks in transmission of $C$. burnetii to humans. The role of these arthropods in transmitting the pathogen to humans or animals is poorly defined (20).

Though the transmission of $C$. burnetii to host animals via a tick bite is evident, such a possibility of transmission to humans is uncertain. It is likely that there exists another possibility of acquiring the infection with potential involvement of ticks. The faeces of infected ticks are heavily contaminated with the microorganisms, which remain viable in the faeces for long periods of time and therefore may be a potential source of infection for humans and animals. Such infected faeces may become powdered and windborne, thereby infecting the upper respiratory tract of humans and animals. Tick faeces are probably the most concentrated substrate of C. burnetii in nature (21).

Oral transmission is less common, but the consumption of contaminated raw milk and dairy-products could be a source of infection. The consumption of unpasteurized goat dairy products causes Q fever in humans. Predominance of Q fever hepatitis was linked to more frequent drinking of raw milk $(7,22)$. On the other hand, drinking milk contaminated with $C$. burnetii has induced seroconversion in human volunteers, without clinical signs. The infection from commercial milk is unlikely because of the pasteurization process. The advent of pasteurization as a standard procedure in milk processing industry has the potential to eliminate the risk of milk transmission (23). However, in the study by Hatchette et al. (2001), consumption of cheese made

Table 1. $Q$ fever - the number of cases and the incidence in European countries

\begin{tabular}{|c|c|c|c|c|c|c|c|c|c|c|c|c|c|c|c|c|c|c|c|c|}
\hline \multirow{3}{*}{$\begin{array}{l}\text { 至 } \\
\text { 它 }\end{array}$} & \multicolumn{20}{|c|}{ Year } \\
\hline & \multicolumn{2}{|c|}{2001} & \multicolumn{2}{|c|}{2002} & \multicolumn{2}{|c|}{2003} & \multicolumn{2}{|c|}{2004} & \multicolumn{2}{|c|}{2005} & \multicolumn{2}{|c|}{2006} & \multicolumn{2}{|c|}{2007} & \multicolumn{2}{|c|}{2008} & \multicolumn{2}{|c|}{2009} & \multicolumn{2}{|c|}{2010} \\
\hline & $\mathrm{n}$ & $\mathrm{i}$ & $\mathrm{n}$ & $i$ & $n$ & i & $\mathrm{n}$ & i & $n$ & i & $\mathrm{n}$ & i & $n$ & $\mathbf{i}$ & $n$ & i & $\mathrm{n}$ & i & $\mathrm{n}$ & i \\
\hline $\mathrm{BiH}$ & 7 & 0.19 & 43 & 1.15 & 20 & 0.53 & 41 & 1.09 & 31 & 0.82 & 44 & 1.17 & 71 & 1.88 & 19 & 0.5 & 30 & 0.8 & 41 & 1.09 \\
\hline$B G$ & 57 & 0.72 & 275 & 3.48 & 80 & 1.02 & 267 & 3.43 & 49 & 0.63 & 27 & 0.35 & 36 & 0.47 & 17 & 0.22 & & & 18 & 0.24 \\
\hline $\mathrm{HR}$ & 51 & 1.13 & 23 & 0.51 & 206 & 4.61 & 104 & 2.34 & 40 & 0.9 & 28 & 0.63 & 43 & 0.97 & 41 & 0.93 & 21 & 0.48 & 24 & 0.55 \\
\hline$C Z$ & 0 & 0 & 0 & 0 & 1 & 0.01 & 0 & 0 & 1 & 0.01 & 0 & 0 & 2 & 0.02 & 0 & 0 & & & 0 & 0 \\
\hline$F$ & & & & & & & 360 & 0.59 & & & & & & & & & & & 288 & 0.46 \\
\hline D & 289 & 0.35 & 191 & 0.23 & 386 & 0.47 & & & 416 & 0.5 & 204 & 0.25 & 82 & 0.1 & & & 191 & 0.23 & & \\
\hline $\mathrm{NL}$ & 14 & 0.09 & 14 & 0.09 & 10 & 0.06 & 20 & 0.12 & 0 & 0 & 12 & 0.07 & & & 1014 & 6.15 & 2317 & 14 & 506 & 3.05 \\
\hline RUS & & & & & & & 125 & 0.09 & 85 & 0.06 & & & 84 & 0.06 & 17 & 0.01 & 124 & 0.09 & 190 & 0.13 \\
\hline SRB & & & & & & & & & 3 & 0.03 & 46 & 0.47 & 12 & 0.12 & 15 & 0.15 & 17 & 0.17 & 24 & 0.24 \\
\hline SK & 0 & 0 & 1 & 0.02 & 0 & 0 & 0 & 0 & 0 & 0 & 0 & 0 & 1 & 0.02 & 0 & 0 & & & & \\
\hline$E$ & 78 & 0.19 & 123 & 0.3 & 120 & 0.29 & 97 & 0.23 & & & 144 & 0.33 & 159 & 0.36 & 119 & 0.26 & 34 & 0.07 & 69 & 0.15 \\
\hline GB & & & & & 56 & 0.09 & 16 & 0.03 & 25 & 0.04 & 171 & 0.28 & 3 & 0 & 46 & 0.08 & & & 29 & 0.05 \\
\hline
\end{tabular}

Federation, SRB - Serbia, SK - Slovakia, E - Spain, GB - United Kingdom. 
from pasteurized goat milk was identified as an independent risk factor for infection. This was the first time that a product made from pasteurized milk has been associated epidemiologically with health risk. The role of drinking unpasteurized milk in the transfer of $C$. burnetii infection is controversial (24).

Shedding of $C$. burnetii in milk by infected dairy animals was well documented. Infected goats excreted bacteria in milk up to 52 days and cows up to 32 months (22). A recent study reported high prevalence (over 94\%) of C. burnetii in the samples of bulk tank milk from U.S. dairy herds tested by PCR (23). Coxiella were detected in the udder and in mammary lymph nodes. Contamination of the mammary lymph and udder can cause chronic infection in animals which could shed Coxiella in milk for a long period and perhaps during successive lactating periods (22).

Human Q fever is an air-borne infection spread usually through inhalation of contaminated aerosols and is primarily transmitted to humans when aerosol is inhaled during or after parturition of infected animals (12). Contamination by aerosols may occur mainly from parturient fluids. Many worldwide Q fever outbreaks are temporally linked to the lambing/kidding/calving season, as birth products from infected animals can be an important source of environmental contamination and transmission to humans via the aerosol route $(25)$.

Exposure to the birth products of infected animals has been shown to be a primary risk factor in Q fever outbreaks (24). After becoming infected, female animals shed large quantities of $C$. burnetii into the environment during abortion or normal delivery through birth fluids, placenta and foetal membranes (22). Aerosols of the micro-organism can persist for days after parturition, despite immediate removal of the highly infectious placenta (24). Sites contaminated by infectious material during birthing events may serve as a source for continued infection in humans and animals for weeks or months because the bacteria are very resistant to both drying and atmospheric agents (20). The organism, even in unfavourable weather conditions, can survive for months in the spore-like form, thus presenting a source of infection even for those who are not in direct contact with animals (4-6).

Moreover, following the parturition, infected animals excrete the bacteria via urine, faeces, vaginal discharges, and milk for several months (22). The hay spread on floors of the pens is spread around and contaminated with C. burnetii present in faeces, urine, and products of conception. Removing the bedding would generate aerosols containing C. burnetii. Contaminated hay and manure are also spread on the rocky ground to fertilize pastures next to the barns. This method of disposal becomes a potential source of exposure for surrounding communities (24). Faecal excretion appears to be an important route of contamination of the environment through spreading contaminated dung onto the fields (22). Moreover, contaminated fields and roads often serve as a reservoir for airborne spread of $C$. burnetii (24). In addition to application of manure, other risk procedures on farms contributed to formation and spreading of aerosols, for example outdoor births, cleaning and drying of newborn animals covered in amniotic fluid, burning the fresh straw bedding and birth products/ foetuses outside and transport of manure and animals through densely populated areas $(24,26)$.

Contaminated clothing or other fomites may retain sufficient number of infectious particles to cause infection in persons without direct animal contact (20), as it occurred in the largest outbreak of Q fever in Slovakia in 1993. The bulk of infection was spread in the local pub through contaminated garments of animal attendants assisting abortions and births of goats. Due to their repeated visits to the local pub the infection most probably spread to other guests by aerosol. A total of 113 persons (103 males, 10 females) contracted Q fever. Ninety-five of them were infected by contact with the goat attendants (84\%), and 18 of them were occupational diseases after direct contact with the infected goats $(11,13)$.

As mentioned before, faeces of ticks contain numerous viable C. burnetii corpuscles (7). Excreta from infected ticks persist in animal fur as a highly infectious dust, permitting aerosol transmission within the flock as well as to humans. This can occur through direct or indirect contact or through shearing. Infectious dust produced by shearing of sheep whose wool was presumably contaminated with infected tick faeces was suspected as another potential source of transmission (27).

It is clear that people can inhale infectious aerosols also in other places: factories processing cotton, wool, hides, furs, meat, milk (7); animal research laboratories and institutions housing parturient ruminants (1); abattoirs (20); veterinary hospitals (28); laundries and dry cleaners (1); factories processing ovine foetal products for cosmetics industry. The following is the first report of a $\mathrm{Q}$ fever outbreak associated with the use of animal products in the cosmetics industry (29).

International literature describes many examples of C. burnetii infection after inhalation of aerosol without direct contact with animals or their products. Aerosol transfer is possible during participation in frequent outdoor activities resulting in exposure to aerosols of dusts from the soil. Risk factors include gardening, working in fields, or construction and public works. Van Woerden et al. (2004) suggested that outbreak of Q fever was associated with renovation of an office block within a cardboard manufacturing plant. One potential source identified was straw board in walls and ceilings disturbed by the renovation work. If a straw board had been contaminated some time in the past with a concentrated source of C. burnetii, drilling into this could have produced a cloud of dust containing large numbers of $C$. burnetii spore-like forms (30). Demonstration of the presence of $C$. burnetii by PCR in the samples from an air-conditioning system supported the view that air-conditioning system could contribute to aerosol transmission of the agent (31). Transmission to humans via aerosol route is possible in common locations of daily human activities: schools, shops, grocery markets, football stadiums, banks, etc. Organisms could be carried there by human foot traffic, wind, birds, or other small animals (4). Also occasional bystanders could contract $C$. burnetii infection from exposure to the contaminated aerosols created from animal excrements as the animals repeatedly passed through villages and towns to their pastures $(11,26)$.

It is well known that people far from the source of infection can acquire $\mathrm{Q}$ fever if they inhale an aerosol containing C. burnetii. Due to a long-term survival of the agent in contaminated environments, under certain conditions $Q$ fever can be considered a wind-borne infection spread from farmlands to the urban areas and many unexpected places $(12,32)$. The bacterium persists in the environment in a resistant spore-like form which may become airborne and transported long distances by the wind (26).

Large outbreaks have been reported among persons residing in cities or towns downwind from sites where infected animals 
are kept $(20,27)$. Dry weather might enhance the dispersion of aerosols (33). Climate and meteorological parameters, such as dry and cold wind, low precipitation, relatively low temperatures, and daily relative humidity, although unfavourable, obviously are not sufficiently unfavourable to destroy these resilient organisms (25). Urbanization of traditionally rural areas may be another factor contributing to the observed increase in town outbreaks $(17,27)$ as well as heliports adjacent to animal farms, pastures, waste storage. Helicopters might facilitate airborne transmission of the infectious agent (34).

\section{Risk Occupations}

The majority of reports describing acute Q fever reported that the most common risk factor for infection was occupational exposure. Q fever is now recognized as an occupational hazard for people who work with animals or animal products. It occurs more commonly in agrarian communities $(35,36)$.

At highest infection risk are people who have close contact with animals, animal production workers - agricultural workers, especially those who assist during parturition (e.g., calving, lambing, kidding). Infections were reported in farm workers: farmers, stockyard workers, sheep shearers, livestock transporters, other people exposed to cattle, sheep or goats or their products, agricultural technical and support staff $(1,20,35)$.

Other risk groups include veterinarians, veterinary technicians, students and personnel at veterinary schools and veterinary hospitals (7). Veterinarians are one of the highest risk groups for occupational infection because of their potential contact with infected animals $(37,38)$. Veterinary students could be potentially considered a population at risk to be affected by some zoonosis, because they usually come into contact with animals and their products during their period of instruction $(39,40)$.

In our previously published papers, the sera of employees and students of the Veterinary University were tested for antibodies to C. burnetii $(38,39)$.

In the group of employees (veterinarians $n=75$, animal attendants $\mathrm{n}=8$, laboratory personnel $\mathrm{n}=7$, technical and administrative personnel $n=2$ ) the results indicate that phase I antibodies were detected in 35 subjects, i.e. in $38 \%$, and phase II antibodies in 58 subjects, i.e. in $63 \%$. Table 2 describes the relation between levels of antibodies and occupational exposure, where the highest levels were confirmed among veterinarians.

In the other published paper, we compared association between C. burnetii seroprevalence and selected risk factors among veterinary students $(n=77)$. Some risk factors may have contributed to the high seroprevalence found in these subjects. For example, there were positive associations with rural life and exposure to the breeding of farm animals, and in addition, work in a dusty environment, such as on fields, gardens, stables and construction sites were also connected to high seroprevalence. The relationship of seroprevalence and consumption of raw milk for phase II antibodies $(\mathrm{p}=0.06)$ was close to the level of significance $(p<0.05)$. Table 3 shows significant differences for phase I and II antibodies to the selected risk factors.

Abattoir workers/employees are a readily identifiable risk group, such as workers who visit or work on an abattoir site. This includes service providers, such as electricians, plumbers, telecommunication workers, weights and measures inspectors, transport workers, contractors to abattoirs, meat packers, meat processing industry workers, and butchers (41).

Laboratory acquisition of $\mathrm{Q}$ fever has been reported since the initial year when Coxiella was isolated. Outbreaks occurred in people working directly with the agent, such as bacteriologists, virologists, and aerosol test unit operators, in workers in research institutions where parturient ruminants were housed, in medical laboratories using sheep for research, and in laboratory personnel handling veterinary specimens $(7,20)$.

Q fever may occur in workers in factories processing cotton, wool, and hides (11), dump-site workers, employees of agricultural training centres, workers in the meat refrigeration depots, dairy industry workers (15), and workers processing animal foetal products for the cosmetics industry (29).

Additional professional risk groups are: registered commercial processors of game meat, kangaroo abattoir workers, camel abattoir workers, workers tanning and processing hides, pet food producers (those who use mixed abattoir material), feedlot workers, registered stock agents, registered livestock auctioneers, taxidermists (35), hunters (42), workers at animal shows/exhibitions and urban farmers markets (4), forestry workers (15), and shepherds (43).

Survival of the organism on inanimate surfaces, such as straw, hay, clothing, or soil allows for transmission to individuals who are not in direct contact with infected animals for example soldiers sleeping in barns previously occupied by infected animals, laundry workers handling infected clothing (1), people working in the building trade, public works, horticulture and postal workers. Employees who are not directly exposed to animals or animal products but who work in a high risk environment are under similar risk of exposure to C. burnetii. C. burnetii is a serious threat for military personnel $(34,35)$.

Undoubtedly, Q fever outbreaks may also occur in the future in other professions that have not yet been registered in the literature

Table 2. Seroprevalence and occupation

\begin{tabular}{|c|c|c|c|c|c|c|c|c|c|c|}
\hline \multirow{3}{*}{$\begin{array}{l}\text { Occupation } \\
\text { Veterinarian }\end{array}$} & \multirow{2}{*}{\multicolumn{2}{|c|}{$\begin{array}{c}\begin{array}{c}\text { Phase I and II } \\
\text { antibodies }\end{array} \\
\text { (titre and number) } \\
1: 100\end{array}$}} & \multirow{2}{*}{\multicolumn{2}{|c|}{$\begin{array}{c}\begin{array}{c}\text { Phase I and II } \\
\text { antibodies } \\
\text { (titre and number) }\end{array} \\
1: 200\end{array}$}} & \multirow{2}{*}{\multicolumn{2}{|c|}{$\begin{array}{c}\begin{array}{c}\text { Phase I and II } \\
\text { antibodies } \\
\text { (titre and number) }\end{array} \\
1: 400\end{array}$}} & \multirow{2}{*}{\multicolumn{2}{|c|}{$\begin{array}{c}\begin{array}{c}\text { Phase I and II } \\
\text { antibodies } \\
\text { (titre and number) }\end{array} \\
1: 800\end{array}$}} & \multirow{2}{*}{\multicolumn{2}{|c|}{$\begin{array}{c}\begin{array}{c}\text { Phase I and II } \\
\text { antibodies } \\
\text { (titre and number) }\end{array} \\
1: 1600\end{array}$}} \\
\hline & & & & & & & & & & \\
\hline & 9 & 15 & 12 & 8 & 2 & 9 & 1 & 6 & - & 3 \\
\hline Animal attendant & 3 & - & - & 3 & - & 3 & - & 2 & 1 & - \\
\hline Laboratory personnel & - & - & 6 & 4 & - & 2 & - & 1 & - & - \\
\hline Technical and administrative personnel & 1 & - & 1 & - & - & 1 & - & - & - & - \\
\hline
\end{tabular}


Table 3. Possible predisposition factors to $Q$ fever

\begin{tabular}{|c|c|c|c|c|c|c|}
\hline Risk factors & Exposure & $\begin{array}{c}+ \text { for phase I } \\
\text { (number) }\end{array}$ & $\mathrm{p}$ & $\begin{array}{c}+ \text { for phase II } \\
\text { (number) }\end{array}$ & $\mathrm{p}$ & $\begin{array}{c}\text { Total No. of } \\
\text { students }\end{array}$ \\
\hline \multirow{2}{*}{ Residence } & Town & 7 & \multirow{2}{*}{0.3613} & 25 & \multirow{2}{*}{0.0408} & 27 \\
\hline & Country & 6 & & 20 & & 50 \\
\hline \multirow{2}{*}{ Presence at parturition or abortion } & Parturition/abortion & 8 & \multirow{2}{*}{0.88} & 25 & \multirow{2}{*}{0.3746} & 46 \\
\hline & - & 5 & & 20 & & 31 \\
\hline \multirow{2}{*}{ Pet ownership } & Pets & 10 & \multirow{2}{*}{0.9777} & 37 & \multirow{2}{*}{0.1686} & 59 \\
\hline & - & 3 & & 8 & & 18 \\
\hline \multirow{2}{*}{ Farm animals ownership } & Farm animals & 5 & \multirow{2}{*}{0.501} & 18 & \multirow{2}{*}{0.017} & 22 \\
\hline & - & 8 & & 27 & & 55 \\
\hline \multirow{2}{*}{ Work in a dusty environment } & Dusty environment & 9 & \multirow{2}{*}{0.8021} & 36 & \multirow{2}{*}{0.0025} & 51 \\
\hline & - & 4 & & 9 & & 26 \\
\hline \multirow{2}{*}{ Tick bite } & Tick & 7 & \multirow{2}{*}{0.33} & 32 & \multirow{2}{*}{0.426} & 52 \\
\hline & - & 6 & & 13 & & 25 \\
\hline \multirow{2}{*}{ Consumption of raw milk } & Raw milk & 2 & \multirow{2}{*}{0.124} & 12 & \multirow{2}{*}{0.067} & 27 \\
\hline & - & 11 & & 33 & & 50 \\
\hline
\end{tabular}

or in professionally disabled people or people in indirect contact with animals and their products.

\section{Prevention and Control of $\boldsymbol{C}$. burnetii Infection}

It includes nonspecific and specific preventive measures. Specific measures include vaccination of at risk individuals. It concerns not only persons exposed professionally to C. burnetii infection (mentioned above), but should probably be considered also in patients at risk for chronic Q fever development (e.g. persons with cardiac valve defects, vascular aneurysms and prostheses and immunocompromised patients) $(12,17,18,44)$. The registered vaccine is Q-VAX (CSL Limited, Parkville, Victoria, Australia). It is prepared from phase I Henzerling strain of $C$. burnetii grown in the yolk sacs of chicken embryos. The organisms are extracted, inactivated with formalin, and freed from excess egg proteins by fractionation and ultracentrifugation (45).

For vaccination of domestic animals, corpuscular phase I or phase II were used. Because the phase II vaccine did not protect animals from shedding C. burnetii in milk, an effective $\mathrm{Q}$ fever vaccine should consist of or be prepared from phase I $C$. burnetii $(11,46,47)$.

The nonspecific preventive measures include: education of the public, persons at risk, and health care professionals on sources of infection; counseling persons with occupational exposures that are at highest risk of developing chronic Q fever, especially persons with pre-existing heart valve disease or individuals with vascular grafts, and immunosuppressed persons; individuals at high risk of chronic $\mathrm{Q}$ fever should undergo regular health checks to promote early recognition of the development of endocarditis (48); acute Q fever patients having recognizable heart valve disease at the time of treatment/diagnosis should be carefully monitored by serologic procedures every three months for the next two years; encourage the public to use only pasteurized milk and milk products; appropriate dispose of placenta, birth products, foetal membranes, and aborted foetuses at facilities housing cattle, sheep, and goats; using quarantine procedures for new animals prior to introduction to a herd; improving veterinary control of transport of domestic animals within the country (11); holding facilities for ruminants should be located away from populated areas to prevent windborne spread of the disease from infected herds; restricted access to barns and laboratories used for housing potentially infected animals; measures should be implemented to prevent air flow to other areas of human or animal occupancy; using appropriate procedures for bagging, autoclaving, and washing of laboratory clothing; complete disinfection of an area, disinfection of the site after parturition (43), disinfection of contaminated animal wastes, keeping in mind that many standard disinfectants are not effective in killing $C$. burnetii, the most effective disinfectants are quaternary ammonium compounds (e.g. Microchem ${ }^{\circledR} 5 \%$ solution); rigorous personal hygiene; standard precautions against exposure through contact by use of gowns and gloves, and through droplets by use of surgical masks (35); animals should be routinely tested for antibodies to C. burnetii; eradication of ticks, control of transmission from ticks to animals must be achieved by rigorous treatment of animals with acaricides (27); crutch-clipping of the ewe's wool prior to lambing and total confinement housing at lambing/kidding/calving (49); installation of ventilations systems with special filters which would prevent C. burnetii from entering; control of animal products and strict hygiene measures on cattle, sheep and goat farms, and in plants processing products of these animals (11); determine optimum treatment combinations and appropriate duration of antimicrobial therapy of Q fever; and many others (50).

\section{CONCLUSION}

C. burnetii is considered a potential agent of bioterrorism because of its accessibility, low infectious dose, resistance to environmental degradation, and aerosol route of transmission. Because the surveillance for $\mathrm{Q}$ fever is currently lacking it 
would be difficult to detect and respond to a bioterrorism event involving C. burnetii. Additional improvements in surveillance, such as increasing physician reporting, making animal infections notifiable, and conducting systematic seroprevalence studies in both humans and animals would provide important information.

Awareness of this disease as a threat to human health and compliance with preventive and control measures must be improved among professionally exposed persons and the public.

Increased awareness among patients and physicians as well as the introduction of rapid laboratory assays, such as PCR, may further reduce the delay between onset of illness, diagnosis and notification. This requires close collaboration between the human and veterinary public health sectors to ensure timely detection of cases, identification of plausible sources and standardised environmental sampling, and application of public health and veterinary preventive measures.

Uncontrolled transport of domestic animals within a country should be stopped and preventive measures implemented, including immunisation with currently available vaccines of domestic animals and humans at risk.

\section{Acknowledgement}

This work was supported by the Grants VEGA No. 1/0359/10 and 1/0198/13 of the Ministry of Education, Science, Research and Sport of the Slovak Republic.

\section{REFERENCES}

1. Byrne WR. Q fever. In: Sidell FR, Takafuji ET, Franz DR, editors. Medical aspects of chemical and biological warfare. Washington, DC: Borden Institute, Walter Reed Army Medical Center; 1997. p. 523-37.

2. Maltezou HC, Constantopoulou I, Kallergi C, Vlahou V, Georgakopoulos D, Kafetzis DA, et al. Q fever in children in Greece. Am J Trop Med Hyg. 2004 May;70(5):540-4.

3. DeForge JR, Cone LA. The serologic prevalence of Q fever (Coxiella burnetii) complement-fixing antibodies in the Peninsular bighorn sheep of Southern California. Am J Trop Med Hyg. 2006 Aug;75(2):315-7.

4. Kersh GJ, Wolfe TM, Fitzpatrick KA, Candee AJ, Oliver LD, Patterson NE, et al. Presence of Coxiella burnetii DNA in the environment of the United States, 2006 to 2008. Appl Environ Microbiol. 2010 Jul;76(13):4469-75.

5. Dorko E, Pilipčinec E. History of Q fever and Coxiella burnetii characteristics. In: Dorko E, Pilipčinec E, editors. Q fever - continually actual zoonosis. Košice: TypoPress; 2005. p. 7-15. (In Slovak.)

6. Literák I, Řeháček J. Q fever - distribution and importance of this disease in the Czech Republic and in the Slovak Republic. Vet Med Czech. 1996;41(2):45-63. (In Czech.)

7. Kovácová E, Kazár J. Q fever - still a query and underestimated infectious disease. Acta Virol. 2002;46(4):193-210.

8. Bacellar F, Dawson JE, Silveira CA, Filipe AR. Antibodies against Rickettsiaceae in dogs of Setúbal, Portugal. Cent Eur J Public Health. 1995 May;3(2):100-2.

9. Dorko E, Pilipčinec E, Rimárová K, Kostovčíková J. Serological study of $\mathrm{Q}$ fever in sheep in the territory of Eastern Slovakia. Ann Agric Environ Med. 2010 Dec;17(2):323-5.

10. Literák I, Calvo Rodríguez B. Latent Q fever in cattle in southern Moravia (Czech Republic). Cent Eur J Public Health. 1994 Dec;2(2):91-4.

11. Serbezov VS, Kazár J, Novkirishki V, Gatcheva N, Kovácová E, Voynova V. Q fever in Bulgaria and Slovakia. Emerg Infect Dis. 1999 MayJun;5(3):388-94.

12. Kazar J. Coxiella burnetii infection. Ann N Y Acad Sci. 2005 Dec;1063:105-14.

13. Varga V. An explosive outbreak of Q-fever in Jedl'ové Kostol'any, Slovakia. Cent Eur J Public Health. 1997 Dec;5(4):180-2.

14. Pospíšil R. Serologic detection of Q fever in Eastern Slovakia. Bratisl Lek Listy. 1956;36:35-8. (In Slovak.)
15. Kapitančik B, Reháček J, Kocianová E, Kováčová E, Nad’ O, Jurčina A. The history of Q fever in Eastern Slovakia. Folia Vet. 1997;41(3-4):103-6.

16. World Health Organization. Centralized information system for infectious diseases (CISID) [Internet]. Geneva: WHO; 2012 [cited 2012 Jul 07]. Available from: http://data.euro.who.int/cisid/.

17. Delsing CE, Kullberg BJ, Bleeker-Rovers CP. Q fever in the Netherlands from 2007 to 2010. Neth J Med. 2010 Dec;68(12):382-7.

18. Dumler JS. Q fever. Curr Treat Options Infect Dis. 2002;4:437-45.

19. Spyridaki I, Psaroulaki A, Loukaides F, Antoniou M, Hadjichristodolou C, Tselentis Y. Isolation of Coxiella burnetii by a centrifugation shell-vial assay from ticks collected in Cyprus: detection by nested polymerase chain reaction (PCR) and by PCR-restriction fragment length polymorphism analyses. Am J Trop Med Hyg. 2002 Jan;66(1):86-90.

20. McQuiston JH, Childs JE. Q fever in humans and animals in the United States. Vector Borne Zoonotic Dis. 2002 Fall;2(3):179-91.

21. Špitalská E, Kocianová E. Detection of Coxiella burnetii in ticks collected in Slovakia and Hungary. Eur J Epidemiol. 2003;18(3):263-6.

22. Arricau Bouvery N, Souriau A, Lechopier P, Rodolakis A. Experimental Coxiella burnetii infection in pregnant goats: excretion routes. Vet Res. 2003 Jul-Aug;34(4):423-33.

23. Kim SG, Kim EH, Lafferty CJ, Dubovi E. Coxiella burnetii in bulk tank milk samples, United States. Emerg Infect Dis. 2005 Apr;11(4):619-21.

24. Hatchette TF, Hudson RC, Schlech WF, Campbell NA, Hatchette JE, Ratnam S, et al. Goat-associated Q fever: a new disease in Newfoundland. Emerg Infect Dis. 2001 May-Jun;7(3):413-9.

25. Karagiannis I, Morroy G, Rietveld A, Horrevorts AM, Hamans M, Francken P, et al. Q fever outbreak in the Netherlands: a preliminary report. Euro Surveill. 2007 Aug 9;12(32). pii: 3247.

26. Wallensten A, Moore P, Webster H, Johnson C, van der Burgt G, Pritchard $\mathrm{G}$, et al. Q fever outbreak in Cheltenham, United Kingdom, in 2007 and the use of dispersion modelling to investigate the possibility of airborne spread. Euro Surveill. 2010 Mar 25;15(12). pii: 19521.

27. Hellenbrand W, Breuer T, Petersen L. Changing epidemiology of Q fever in Germany, 1947-1999. Emerg Infect Dis. 2001 Sep-Oct;7(5):789-96.

28. Komiya T, Sadamasu K, Toriniwa H, Kato K, Arashima Y, Fukushi H, et al. Epidemiological survey on the route of Coxiella burnetii infection in an animal hospital. J Infect Chemother. 2003 Jun;9(2):151-5.

29. Wade AJ, Cheng AC, Athan E, Molloy JL, Harris OC, Stenos J, et al. Q fever outbreak at a cosmetics supply factory. Clin Infect Dis. $2006 \mathrm{Apr}$ $1 ; 42(7): \mathrm{e} 50-2$

30. van Woerden HC, Mason BW, Nehaul LK, Smith R, Salmon RL, Healy B, et al. Q fever outbreak in industrial setting. Emerg Infect Dis. 2004 Jul;10(7):1282-9.

31. Amitai Z, Bromberg M, Bernstein M, Raveh D, Keysary A, David D, et al. A large $Q$ fever outbreak in an urban school in central Israel. Clin Infect Dis. 2010 Jun 1;50(11):1433-8.

32. Rosický B, Minár J. The role of the National Institute of Public Health in the field of infections with natural focality. Cent Eur J Public Health. 1996 May;4(2):123-6.

33. Tissot-Dupont H, Amadei MA, Nezri M, Raoult D. Wind in November, Q fever in December. Emerg Infect Dis. 2004 Jul;10(7):1264-9.

34. Špliňo M, Beran J, Chlíbek R. Q fever outbreak during the Czech Army deployment in Bosnia. Mil Med. 2003 Oct;168(10):840-2.

35. Reid A, Malone J. Q fever in Ireland. A seroprevalence study of exposure to Coxiella burnettii among Department of Agriculture workers. Occup Med (Lond). 2004 Dec;54(8):544-7.

36. Literák I. Prevalence of antibodies to Coxiella burnetii in blood donors in the Czech Republic. Cent Eur J Public Health. 1994 Jun;2(1):52-4.

37. Abe T, Yamaki K, Hayakawa T, Fukuda H, Ito Y, Kume H, et al. A seroepidemiological study of the risks of Q fever infection in Japanese veterinarians. Eur J Epidemiol. 2001;17(11):1029-32.

38. Dorko E, Kalinová Z, Weissová T, Pilipčinec E. Seroprevalence of antibodies to Coxiella burnetii among employees of the Veterinary University in Košice, Eastern Slovakia. Ann Agric Environ Med. 2008 Jun;15(1):119-24.

39. Dorko E, Rimárová K, Kecerová A, Pilipčinec E, Dudríková E, Lovayová $\mathrm{V}$, et al. Potential association between Coxiella burnetii seroprevalence and selected risk factors among veterinary students in Slovakia. Ann Agric Environ Med. 2011 Jun;18(1):47-53.

40. Valencia MCS, Rodriguez CO, Puñet OG, de Blas Giral I. Q fever seroprevalence and associated risk factors among students from the Veterinary School of Zaragoza, Spain. Eur J Epidemiol. 2000 May;16(5):469-76.

41. Bell M, Patel M, Sheridan J. Q fever vaccination in Queensland abattoirs. Commun Dis Intell. 1997 Feb 6;21(3):29-31. 
42. Gami AS, Antonios VS, Thompson RL, Chaliki HP, Ammash NM. Q fever endocarditis in the United States. Mayo Clin Proc. 2004 Feb;79(2):253-7.

43. Dolcé P, Bélanger MJ, Tumanowicz K, Gauthier CP, Jutras P, Massé R, et al. Coxiella burnetii seroprevalence of shepherds and their flocks in the lower Saint-Lawrence River region of Quebec, Canada. Can J Infect Dis. 2003 Mar;14(2):97-102.

44. Fenollar F, Fournier PE, Carrieri MP, Habib G, Messana T, Raoult D. Risks factors and prevention of Q fever endocarditis. Clin Infect Dis. 2001 Aug 1;33(3):312-6.

45. Q-VAX (R). Q fever vaccine [Internet]. 2009 [cited 2012 Jul 02]. Available from: http://www.csl.com.au/docs/928/402/Q-vax\%20CMI\%20 May2009.pdf.

46. Kazár J, Gajdošová E, Kováčová E, Valková D. Immunogenicity and protective ability of corpuscular and soluble vaccines prepared from different Coxiella burnetii phase I strains. Acta Virol. 1995 Dec;39(56):243-9
47. Souriau A, Arricau-Bouvery N, Bodier C, Rodolakis A. Comparison of the efficacy of $\mathrm{Q}$ fever vaccines against Coxiella burnetii experimental challenge in pregnant goats. Ann N Y Acad Sci. 2003 Jun;990:521-3.

48. Madariaga MG, Pulvirenti J, Sekosan M, Paddock CD, Zaki SR. Q fever endocarditis in HIV-infected patient. Emerg Infect Dis. 2004 Mar;10(3):501-4.

49. Lang G, Waltner-Toews D, Menzies P. The seroprevalence of coxiellosis (Q fever) in Ontario sheep flocks. Can J Vet Res. 1991 Apr;55(2):139-42.

50. Calza L, Attard L, Manfredi R, Chiodo F. Doxycycline and chloroquine as treatment for chronic Q fever endocarditis. J Infect. 2002 Aug;45(2):127-

Received December 10, 2012 Accepted in revised form July 9, 2012 